\title{
O PAPEL DO CONSELHO FEDERAL DA ORDEM DOS ADVOGADOS DO BRASIL NO CONTROLE DE CONSTITUCIONALIDADE DE DIREITOS FUNDAMENTAIS
}

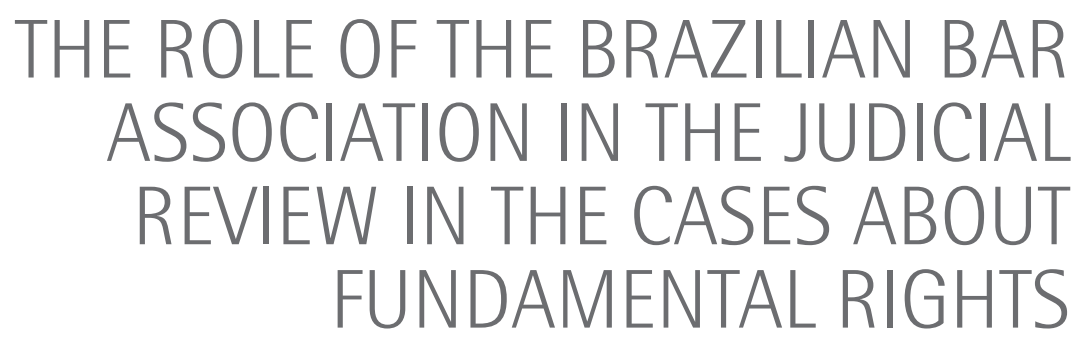

Lilian Marcia Balmant Emerique lilamarcia@gmail.com

Verônica Ferreira Noronha de Barros

Mariana Moretti Ribeiro

Recebido: 29-05-2016

Aprovado: 17-02-2018

Sumário: 1. Consideraçóes Iniciais. 2. Participação popular e jurisdição democrática. 3. Sociedade aberta de intérpretes da constituição. 4. Análise das açốes diretas de inconstitucionalidade propostas pelo conselho federal da ordem dos advogados do Brasil. 5. Consideraçóes finais. Referências.

RESUMO:

Estudo empírico das Ações Direitas de Constitucionalidade (ADIs) propostas pelo Conselho Federal da Ordem dos Advogados do Brasil (CFOAB), verificando marco de interpretação da constituição em sentido pluralista de acordo com a ideia de sociedade aberta de intérpretes da Constituição, de Peter Häberle, também observando aspectos da participação popular (sociedade civil) para uma jurisdição democrática. Utilizou-se metodologia de pesquisa empírica e análise das ADIs movidas pelo CFOAB (período entre 1988 - 2014). Resultado pontua contribuição relevante CFOAB para demo-

\section{ABSTRACT:}

Search examine the constitutional suits filed by the Federal Council of the Bar Association of Brazil (CFOAB in Portuguese), seeking empirically verify that, over time (1988 - 2014), the interpretation of the constitution has been pluralistic in accordance with the idea of an open society of interpreters of Peter Häberle, also observing aspects of popular participation (civil society) to a democratic jurisdiction. The methodology used was the cataloging Actions proposals by CFOAB and also a critical analysis of information. The result shows CFOAB important contribution as an important 
cracia no controle de constitucionalidade de direitos fundamentais.

\section{PALAVRAS CHAVE:}

Ação Direita de Inconstitucionalidade (ADI), Conselho Federal da Ordem dos Advogados do Brasil (CFOAB), controle de constitucionalidade. factor in democracy the fundamental rights of judicial review.

\section{KEY WORDS:}

Federal Council Brazilian Bar Association (CFOAB in Portuguese), judicial review, Direct Unconstitutionality Action (ADI in Portuguese).

\section{CONSIDERAÇÕES INICIAIS}

Muito se discute a respeito do controle de constitucionalidade, tanto no Brasil, quanto nos diversos países espalhados pelo mundo. Há inúmeras obras vocacionadas a discutir aspectos teóricos e práticos desse tema, porém ainda existem campos a serem explorados e/ou aprofundados. Geralmente, as matérias aventadas nas abordagens tradicionais situam-se em torno de discussóes sobre o sistema de controle, as dimensóes processuais dos instrumentos de controle (ações), e o resultado das ações interpostas focalizadas no órgão julgador ou órgãos julgadores, conforme o tratamento em termos de controle concentrado ou difuso de constitucionalidade.

Há uma lacuna de estudos teóricos e empíricos que abordem os demais atores que participam do processo de controle de constitucionalidade e desvendem aspectos teóricos e práticos relacionados ao papel que desempenham na atuação direta nos instrumentos de controle, enquanto legitimados ativos para propositura das açóes pertinentes.

Esta lacuna de abordagem pode criar a impressão equivocada de que a atividade jurisdicional e o controle de constitucionalidade por ela exercido é o que de fato importa na construção de análises sobre os processos de imersão da constituição na sociedade, ignorando os demais atores que postulam no controle concentrado de constitucionalidade e vocalizam demandas da própria sociedade, inclusive com repercussóes claras na área dos direitos fundamentais.

Esta visão parcial tem a desvantagem de deixar de lado aspectos importantes sobre os ganhos da vivência social da Constituição, os processos de participação que reflitam dimensóes democratizantes da sociedade, a pluralidade dos atores que contribuem efetivamente para a concretização constitucional, a construção de um sentimento constitucional $^{1}$ (VERDÚ, 2004, p. 75-77), dentre outras ricas possibilidades de compreensão do fenômeno constitucional.

\footnotetext{
Segundo Pablo Lucas Verdú, "sentimento constitucional consiste na adesão interna às normas e instituições fundamentais de um país, experimentada com intensidade mais ou menos consciente porque estima-se (sem que seja necessário um conhecimento exato de suas peculiaridades e funcionamento) que são boas e convenientes para a integração, manutenção e desenvolvimento de uma justa convivência." E ainda, "Por conseguinte, o sentimento constitucional tende a persistir, apesar de sua instabilidade. É espontâneo - ainda que estimulado pelo contexto, pelo ambiente ideológico e pela situação sociopolítica-, público e representativo, mostrando, além disso, certa expansividade. Quanto à dinâmica do sentimento constitucional, é preciso sublinhar o grau de aceitação e adesão às normas fundamentais, não esquecendo a luta pela Constituição, tanto nos momentos culminantes de máxima emotividade constitucional (periodos constituintes ..., como nos momentos normalizados. Além disso, deve considerar-se o grau de cumprimento dos deveres constitucionais."
} 
Por esse motivo, o presente trabalho objetiva deslocar o foco da discussão tradicionalmente situado no órgão julgador (Supremo Tribunal Federal) e o seu comportamento ou avaliação das decisóes proferidas colocando foco nos legitimados ativos para a propositura das açóes de controle de constitucionalidade previstas pela Constituição. A análise estará especialmente direcionada para a participação do Conselho Federal da Ordem dos Advogados do Brasil (CFOAB) nas açóes diretas de inconstitucionalidade movidas dentro do sistema repressivo e concentrado de controle de constitucionalidade brasileiro em matéria de direitos fundamentais, com vistas a uma jurisdição democrática.

Cumpre lembrar que antes da existência do rol ampliado para propositura das Açóes Diretas de Inconstitucionalidade, quem podia questionar a constitucionalidade de uma norma perante o STF era o Procurador-Geral da República, o qual detinha este poder exclusivamente. Esta manifestação dava-se por meio da Representação de Inconstitucionalidade perante o STF.

Entretanto, com a Constituição de 1988, batizada como "Constituição cidadâ", houve uma ampliação no rol dos legitimados ativos habilitados para concorrentemente questionar a constitucionalidade de leis, tanto federais como estaduais, perante o STF.

Assim o rol foi estendido e passou a contemplar:

- O Presidente da República,

- A Mesas do Senado-Federal;

- A Mesa da Câmara dos Deputados,

- A Mesa de Assembleia Legislativa ou da Câmara Legislativa do Distrito Federal;

- Os Governadores de estado e do Distrito Federal;

- O Procurador-Geral da República,

- Os partidos políticos com representação no Congresso Nacional,

- As confederaçôes sindicais ou entidades de classe de âmbito nacional,

- O Conselho Federal da Ordem dos Advogados do Brasil (art. 103 da CRFB/88).2

Dentre todos os legitimados ativos enumerados no art.103 da Constituição, optou-se por estudar o CFOAB por ser um ator sem a necessidade de comprovação da pertinência temática ${ }^{3}$, ou seja, este poderá propor açóes constitucionais sobre quaisquer temas sem

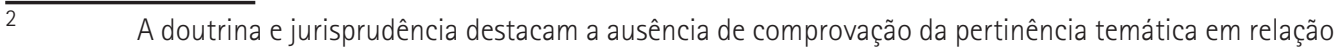
às ações constitucionais de controle de constitucionalidade propostas pelo Conselho Federal da OAB e a ampliação do rol dos legitimados ativos destas ações é mencionada como um ganho para a democracia brasileira, após largo período de ditadura e desrespeito aos direitos fundamentais. Aliás, por este motivo e devido a forte militância da $\mathrm{OAB}$ em favor da redemocratização do país e também durante as atividades da Assembleia Constituinte que originou a atual constituição, somados ao empenho para assegurar que a Constituição ocuparia efetivamente o lugar de supremacia e defesa dos direitos fundamentais, foi conferida ao Conselho Federal da $O A B$ a condição de legitimado ativo destas ações.

3 Pertinência temática é um requisito objetivo da relação de pertinência entre a defesa do interesse específico do legitimado e o objeto da própria ação, isto é, consiste na necessidade de demonstração, por alguns legitimados (p. ex: entidades de classe e confederações sindicais), de que o objeto da instituição guarda relação (pertinência) com o pedido da ação proposta.
} 
restriçôes e não somente aqueles relacionados à sua área de atuação, uma vez que conta com legitimação ativa universal. ${ }^{4}$

O estudo que aqui se empreende tem por propósito proceder à análise empírica da conformidade entre a teoria e prática no que toca ao papel desempenhado pelo CFOAB na condição de legitimado ativo no controle de constitucionalidade repressivo e concentrado, em face da autorização constitucional para a propositura de ADIs, avaliando este papel à luz do referencial teórico de sociedade aberta dos intérpretes da constituição (Häberle) numa perspectiva que prima pela pluralidade interpretativa e procedimental da Constituição, bem como pelo viés da participação popular (sociedade civil) na composição de uma jurisdição democrática.

Especialmente com respeito às Ações Diretas de Inconstitucionalidade (ADI's), é sabido que se trata de uma ferramenta constitucional eficaz contra leis e atos normativos federais e estaduais que afrontem preceitos constitucionais. Por meio delas é realizado o controle repressivo e concentrado de constitucionalidade pelo Supremo Tribunal Federal (STF) que produz efeito erga omnes e vinculante (quando assim decidido pelo STF - art. 103-A da CRFB/88). Sendo assim, sua decisão valerá para toda a sociedade e vinculará todos os órgãos judiciais, os quais só poderão decidir no mesmo sentido do entendimento do STF.

A presente pesquisa concentra seu foco nas Ações Diretas de Inconstitucionalidade por representarem a imensa maioria das açóes constitucionais propostas pelo $\mathrm{CFOAB}$, não chegando as demais a um número considerável. Além disso, há a questão da temporariedade, já que elas apresentam uma dimensão temporal maior, posto que sua existência antecede as outras açóes de controle de constitucionalidade admitidas em nosso sistema.

\section{PARTICIPAÇÃO POPULAR E JURISDIÇÃO DEMOCRÁTICA}

Até as últimas décadas do século passado, eram comuns, na literatura internacional, expressões pessimistas sobre a criação de canais participativos nos países em desenvolvimento, em razão das características de suas instituições políticas e de seus atores políticos. Conjecturava-se que as instituiçóes estariam dominadas por pactos e acertos elitistas informais e pela debilidade da sociedade civil (GRINDLE \& THOMAS, 1991; MIDGLEY, 1986; UGALDE, 1985).

Em posição contrária a tais proposições, vários autores sublinham a criação de mecanismos de participação em diferentes áreas e níveis administrativos no Brasil (BULHÕES, 2002; DAGNINO, 2002; RAICHELES, 2000; SANTOS JÚNIOR, 2001; TATAGIBA, 2002). Dentre esses se destacam inúmeros conselhos de políticas públicas, em diversas áreas.

Contudo, não podemos olvidar que estes avanços também permearam não apenas a Administração Pública, mas também foram inseridos canais abertos para participação, ainda que em menor escala, no âmbito do Poder Judiciário, configurando aspectos de democratização da jurisdição (por exemplo: ampliação dos legitimados ativos nas ações

\footnotetext{
$4 \quad$ Há certa simetria entre o artigo 103 da CRFB/88 e dispositivos correlatos nas constituições estaduais. Por exemplo, o art. 90 da Constituição do Estado de São Paulo prevê legitimação ativa para propor ação de inconstitucionalidade de leis ou atos normativos estaduais ou municipais para o Conselho da Seção Estadual da Ordem dos Advogados do Brasil (São Paulo).
} 
de controle de constitucionalidade; admissão de amicus curiae; audiências públicas no Poder Judiciário).

A participação - normalmente qualificada como participação cidadã, social, cívica ou comunitária - em políticas públicas, inclusive em políticas públicas no campo da prestação jurisdicional, se converteu em símbolo gerador de afinidades ou antipatias carentes de uma significação consistente.

$\mathrm{Na}$ versão mais otimista a participação pode facilitar a redução do gasto público (p. ex., no orçamento participativo), regenerar o tecido associativo, incrementar a confiança comunitária, fortalecer o espírito crítico, desburocratizar a administração e desenvolver a eficácia da gestâo pública ou da prestação jurisdicional.

Contudo, este recurso tão promissor causa algum ceticismo quando visto na sua prática. Apesar do interesse que suscitam no terceiro setor, nas ONGs e na sociedade civil, a realidade geralmente aponta que a população é apática ou as ofertas participativas não são suficientemente sugestivas ou representativas dos seus interesses. Sem desmerecer os esforços para mobilizar a participação na atualidade, a realidade cotidiana demonstra ser mais pobre, menos vistosa e carente de atenção. Talvez a participação não seja tão sensível ou ofereça contrapartidas, condiçóes, valores e objetivos de tensão.

Assim, a participação institucionalizada repousa sobre princípios de cidadania, direito, igualdade e justiça, apoiada em base ideológico-teórica que, de certa forma, enfatiza a bondade da entrada dos cidadãos na política e nas organizaçóes onde esta é levada a cabo, contudo, na prática existem inúmeras dificuldades de aplicação expostas nas críticas que indicam ser uma participação limitada em seus procedimentos e conteúdos ao marco institucional. Seus procedimentos, muitas vezes visam garantir a estabilidade e legitimidade das instituiçôes, geralmente obedecendo à essência da democracia representativa formal, pois não incluem a igualdade social entre as suas preocupações, nem a consideram prérequisito, nem objetivo da participação.

Deste modo, se servem das fórmulas de delegação de poder como mecanismos mais frequentes de funcionamento, ou seja, revelam compatibilidade com mecanismos pouco democráticos (negociações de âmbito privado, exclusão de grupos, tomada de decisóes prévias ao debate) e são capazes de adaptação a qualquer das necessidades das instituiçóes a que estão ligadas. Politicamente se dirigem a adaptação e a colaboração entre as partes. Reconduzem as propostas mais radicais a procedimentos moderados e favorecem, em várias situaçóes, aos grupos com maior capacidade de resposta e mais familiarizados com o funcionamento e as formas institucionais (SASTRE, 2005, p. 204-205).

O Brasil, principalmente a partir da promulgação da Constituição de 1988, tem experimentado inovaçóes institucionais participativas ${ }^{5}$ que estimulam a interlocução entre Estado e sociedade civil no planejamento da ação governamental e no processo de formatação de políticas públicas e nas questôes relativas à jurisdiçâo democrática.

A participação social pode autorizar, por meio de um processo dialógico, deliberativo, público e de construção de consensos, que atores sociais desempenhem atividades de protagonistas em determinados processos decisórios na articulaçáo com o Poder Público e suas instituiçôes. Emerge daí a possibilidade de desenvolvimento de um

\footnotetext{
Esses novos modelos de instâncias participativas tiveram em comum a proposta de formalizar canais de compartilhamento do poder e circulação de informações entre Estado e Sociedade, mas foram institucionalizadas de inúmeras maneiras, tais como instâncias de deliberação vinculante como os Orçamentos Participativos - OP, instâncias de cogestão e controle social, como os Conselhos setoriais de políticas públicas, instâncias de consulta, como as Audiências Públicas, instâncias de formação da política e construção da agenda, como as Conferências nas mais diversas áreas em âmbito nacional, estadual e municipal.
} 
formato de gestão pública mais democrática e colaborativa, em que o Estado descentraliza sua administraçáo junto à sociedade civil, conferindo aos envolvidos a oportunidade de estabelecer novas capacidades cognitivas, para a ação coordenada nas etapas do ciclo de planejamento do Estado.

Portanto, a determinação dos objetivos das políticas públicas só tem sentido real a partir da participação cidadá, sendo este um objetivo público de primeira ordem, uma vez que constitui a essência da democracia e tem lugar elevado entre os parâmetros centrais de bom governo e boa administração. A participação não se formula apenas como objetivo, as políticas públicas reclamam a prática da participação como método.

Enquanto método, a participação trata da abertura do governo, da administração pública e dos demais poderes (Legislativo e Judiciário) à sociedade. Uma organização fechada, volvida sobre si mesma, não capta, representa ou serve aos interesses próprios das pessoas. A primeira condição para esta abertura é uma atitude, uma disposição, afastada da autossuficiência e prepotência e uma disposição para instituir processos e instrumentos que as tornem reais (RODRÍGUEZ-ARANA, 2012, p. 29).

O mesmo ocorre no campo de políticas públicas relativas ao Poder Judiciário, quebrando a tradicional relação da prestação jurisdicional fechada em si mesma e abrindose para, pelo menos num primeiro momento, incluir novos atores demandantes e em momentos de decisóes cruciais ouvirem a sociedade civil. Enfim, observa-se que alguns receios tradicionais de que a participação poderia desvirtuar a prestação jurisdicional ou mesmo politizar a Justiça, não tem um fundamento claro e, por isso, foram ganhando força as projeções em torno de abertura da interpretação constitucional e a construção de um modelo de jurisdição mais democrática.

\section{SOCIEDADE ABERTA DE INTÉRPRETES DA CONSTITUIÇÃO}

Peter Häberle (1997), em "Hermenêutica constitucional, a sociedade aberta dos intérpretes da Constituição: contribuição para a interpretação pluralista e "procedimental" da Constituição", traz um olhar renovado sobre a interpretação constitucional, com o método concretista de "Constituição aberta", pelo qual defende a democratização do processo interpretativo.

Segundo Mendes (2009), a influência do pensamento de Häberle é sentida na América Latina e no Brasil:

Peter Häberle é certamente um dos maiores constitucionalistas de nosso tempo e, não seria demais considerar, um dos grandes nomes da história do constitucionalismo ocidental. Essa não é, de nenhuma maneira, uma afirmação vaga ou imprecisa, e muito menos hiperbólica. A difusão transnacional de seu pensamento, quase sempre acompanhada de processos formais de institucionalizaçáo de estruturas, organismos e procedimentos voltados à implementação prática dos institutos por ele concebidos em nível doutrinário, é capaz de revelar os sólidos fundamentos que suas criaçôes fornecem para o desenvolvimento do Estado constitucional em tempos hodiernos.

O modelo tradicional de interpretação póe foco em dois aspectos: o que é a interpretação, ou seja, quais são suas tarefas e objetivos, e como se deve fazê-la, seu método. 
O autor propõe uma apreciação sob um novo aspecto, até então não suscitado: o contexto em que a interpretação constitucional se insere, quem são "os agentes conformadores da 'realidade constitucional'” (HÄBERLE, 1997, p. 12). Ele afirma que a interpretação da Constituição não pode ser avaliada como um exercício isolado da realidade prática (um exemplo é o próprio alargamento do escopo de "legitimados" a propor ADIs no STF no Brasil, que é uma reivindicação do processo de democratização, após a ditadura militar).

A construção teórica de Häberle desdobra-se através de três pontos principais: o alargamento do círculo de intérpretes da constituição; o conceito de interpretação como um processo aberto ao público e a referência desse conceito à constituição mesma, como realidade constituída.

A Sociedade Aberta, na acepção de Häberle (1997, p. 13), tem um dúplice papel: ela é tanto o objetivo como a criadora desta interpretação, visto que, enquanto o método constitucional visa atender às perspectivas dos grupos sociais (potências públicas) - e, por esta razão, é objetivo -, também é influenciada por estes no processo criativo da interpretação constitucional, isto é:

A interpretação constitucional é, em realidade, mais um elemento da sociedade aberta. Todas as potências públicas, participantes materiais do processo social, estão nela envolvidas, sendo ela, a um só tempo, elemento resultante da sociedade aberta e um elemento formador ou constituinte dessa sociedade.

A sociedade aberta é aquela que envolve a participação, direta ou indireta, dos agentes sociais no processo hermenêutico, incumbindo aos mesmos à função de intérprete e a de destinatário. Com isso, pode ocorrer a ruptura do monopólio estatal da interpretação constitucional, pela admissão da participação, dos intérpretes tradicionais da norma jurídica (juízes e políticos), bem como daqueles que operam como co-intérpretes (experts, grupos singulares, organizaçóes religiosas, imprensa, etc.), exercendo influência no processo criativo, para Häberle (1997, p. 15):

Todo aquele que vive no contexto regulado por uma norma e que vive com este contexto é, indireta ou, até mesmo diretamente, intérprete dessa norma. O destinatário da norma é participante ativo, muito mais ativo do que se pode supor tradicionalmente, do processo hermenêutico. Como não são apenas os intérpretes jurídicos da Constituição que vivem a norma, não detêm eles o monopólio da interpretação da constituição.

$\mathrm{Na}$ sociedade aberta a interpretação constitucional não é um evento exclusivamente do Estado, porém é produto de um conjunto de fatores sociais, provocados por grupos e indivíduos que influenciam tanto no momento da criação quanto na concretização a norma jurídica.

A legitimação referida por Häberle não se trata daquela teorizada por Luhmann em "Legitimação pelo procedimento". A primeira demanda a participação qualitativa e de conteúdo dos intérpretes (em sentido lato e estrito) para se conseguir a legitimação da jurisdição constitucional, já a teorizada por Luhmann, prediz a acomodação com o procedimento adequado e sujeitos legitimados para construir uma correta interpretaçáo, nas palavras de Häberle (1997, p. 31-32): 
Também a 'legitimação pelo procedimento' no sentido de Luhmann é uma legitimação mediante a participação no procedimento. Todavia, trata-se aqui de algo fundamentalmente diferente: participação no processo não significa aptidão para aceitação de decisóes e preparação para se recuperar de eventuais decepçôes. Legitimação, que não há de ser entendida apenas em sentido formal, resulta da participação, isto é, da influência qualitativa e de conteúdo dos participantes sobre a própria decisão. Não se trata de um 'aprendizado' dos participantes, mas de um 'aprendizado' por parte dos Tribunais em face dos diversos participantes.

Deve-se levar em conta a dinâmica republicana, uma vez que a análise é sob uma perspectiva "sócio constitucional, consequência do conceito 'republicano' de interpretação aberta que há de ser considerada como objetivo da interpretação constitucional." (HÄBERLE, 1997, p. 19).

A república está associada ao direito. A consagração da lei acima dos interesses particulares já indica que se trata da coisa pública e não privada, e aí se encaixa o princípio republicano da prioridade conferida ao coletivo. Sendo certo que o público tem que ser responsável, autor do bem comum, exercendo o controle popular sobre os governantes (seus representantes), tornando o poder mais democrático. Assim, quanto mais republicanas forem as pessoas, participando, mais democrático será o poder.

$\mathrm{Na}$ perspectiva de Häberle, as proposiçóes constitucionais se aderem a publicidade e o direito constitucional é o direito público do bem comum. Toda Constituição tem de ocupar um lugar firme na consciência e na opiniáo pública. A publicidade cria e estimula os processos públicos. Somente alcança força normativa se seus conteúdos são ótimos e se transformam em seu objeto. Daí a importância funcional da publicidade, pois como a mesma res publica se constitui mediante a Constituição aberta. Os direitos fundamentais procuram tanto liberalizar ao Estado como também fazê-lo público e o mesmo cabe dizer da res publica, a democracia e do Estado social de Direito. A Constituição da res publica implica uma relação com a publicidade.

Nestecontexto, vale ressaltar a importância do ideal da república nas três esferas de poder e, além disso, o compromisso republicano materializado na ordem constitucional compóe um importante cenário para a ação republicana no processo de interpretação constitucional que deve resvalar, necessariamente, para o controle de constitucionalidade, conduzindo-o mais adiante do interesse particular previsto no controle difuso de constitucionalidade e ampliando-se num ponto de vista republicano para o controle concentrado, mediante o reconhecimento da sociedade aberta aos intérpretes da constituição, num autêntico ato de cuidado da coisa pública e de promoção da igualdade, tal como mencionado por Häberle.

Deste modo, "um cidadão que formula um recurso constitucional é intérprete da Constituição tal como o partido político que propóe um conflito entre órgãos". Por isso, para Häberle (1997, p. 23) a abertura é indispensável, pois

A interpretação constitucional é, todavia, uma 'atividade' que potencialmente, diz respeito a todos. Os grupos mencionados e o próprio indivíduo podem ser considerados intérpretes constitucionais indiretos ou a longo prazo. A conformação da realidade da Constituição torna-se também parte da interpretação de normas constitucionais pertinentes a essa realidade. 
A democracia de Häberle, sensível a uma espécie de metodologia tópica e concretista, a que serve de escudo, não é a do povo-massa, absoluto, possuidor de um novo gênero de direito divino, mas a do povo-cidadão, artífice de uma democracia de cidadãos, um povo que atua como "partido político, como opinião científica, como grupo de interesse (...)" (HÄBERLE, 1997, p. 37).

Sobre as possíveis indagaçóes a respeito dessa nova proposta, uma, relevante, é que dependendo de como essas interpretaçóes plurais se desdobrariam, poderiam criar uma dissolução da unidade de interpretação. A primeira observação relevante é que a teoria dessa unidade constitucional pode ser questionada. A segunda é que entidades legitimadas gozariam de demais poderes, enquanto as que estão vinculadas "apenas por intermédio do Poder Estatal sancionador" teriam um poder mais restrito.

A legitimação dos outros grupos, que formaria uma interpretação plural, aberta, consiste no fato de que o direito, como ciência humana aplicada, deve, essencialmente, atentar para a realidade, estar em conformidade com ela: "A norma não é uma decisão prévia, simples e acabada, há de se indagar sobre os participantes no seu desenvolvimento funcional, sobre as forças ativas da law in public action"e, ainda, se "essas forças pluralistas representam um pedaço da publicidade e da realidade da Constituição” (HÄBERLE, 1997, p. 31).

Em suma,

[...] uma Constituição que estrutura não apenas o Estado em sentido estrito, mas também a própria esfera pública, dispondo sobre a organização da própria sociedade e, diretamente, sobre setores da vida privada, não pode tratar forças sociais e privadas como mero objeto. Ela deve integrá-las ativamente enquanto sujeitos (HÄBERLE, 1997, p. 33).

O bom êxito da metodologia proposta por Häberle ficará a depender de um não afrouxamento da normatividade pelos órgáos constitucionais judicantes na medida em que estes fizerem uso dos novos instrumentos hermenêuticos, nascidos da necessidade de maior adequação da Constituição com a realidade, bem como do dinamismo normativo do Estado social, o Estado que constrói o futuro da sociedade democrática.

Há ainda a crítica contundente de Verdú (1993, p. 37) de que Häberle insiste mais na publicidade como o eixo central de toda Constituição do que em sua abertura propriamente dita. Em seu entender:

Ciertamente, toda publicidade em cuanto Öffentlich-keit supone abrirse frente al hermetismo, pero la publicidad no agota la apertura, puesto que puden darse otros modos de apertura que no son siempre públicos. A no ser que por publicidad se entienda um concepto omnicomprensivo. El hecho de que la Constitución sea um texto escrito codificado, solemnemente publicado, aplicado, interpretado y, por tanto, sea law in public action, no coincide forzosamente, com apertura. [...] A veces la lectura de sus escritos produce la sensación que el autor se fija más em las características de la sociedad aberta frente a la hermética y las traslada a la Constitución sin más. Esto no es incorrecto pero insuficiente porque conviene, también, isisto, em señalar las notas de la apertura constitucional. 
A interpretação constitucional não é matéria de exclusividade de uns poucos, mas antes um esforço coletivo, republicano e democrático, integrando a sociedade no processo. Neste ponto, faremos a seguir um mapeamento de natureza empírica sobre o processo de ampliação do rol dos legitimados ativos no processo de controle de constitucionalidade, fixando o olhar sobre o Conselho Federal da OAB na figuração de um modelo um pouco mais aberto de intérpretes da constituição.

\section{ANÁLISE DAS AÇÕES DIRETAS DE INCONSTITUCIONALIDADE PROPOSTAS PELO CONSELHO FEDERAL DA ORDEM DOS ADVOGADOS DO BRASIL ${ }^{6}$}

A análise empírica das ADIs propostas entre os anos de 1988 e 2013 pelo CFOAB revela aspectos interessantes sobre a contribuição da instituição no processo de controle de constitucionalidade e, de certa forma, trarão indícios sobre seu aporte para construção de um processo mais plural de interpretaçáo constitucional, num contexto de sociedade aberta dos intérpretes da constituição (Häberle).

É o que se verá a partir do gráfico a seguir no qual se faz menção a percentagem de ADIs propostas entre 1988 e 2013 pelo CFOAB face aos outros legitimados ativos universais e não-universais.

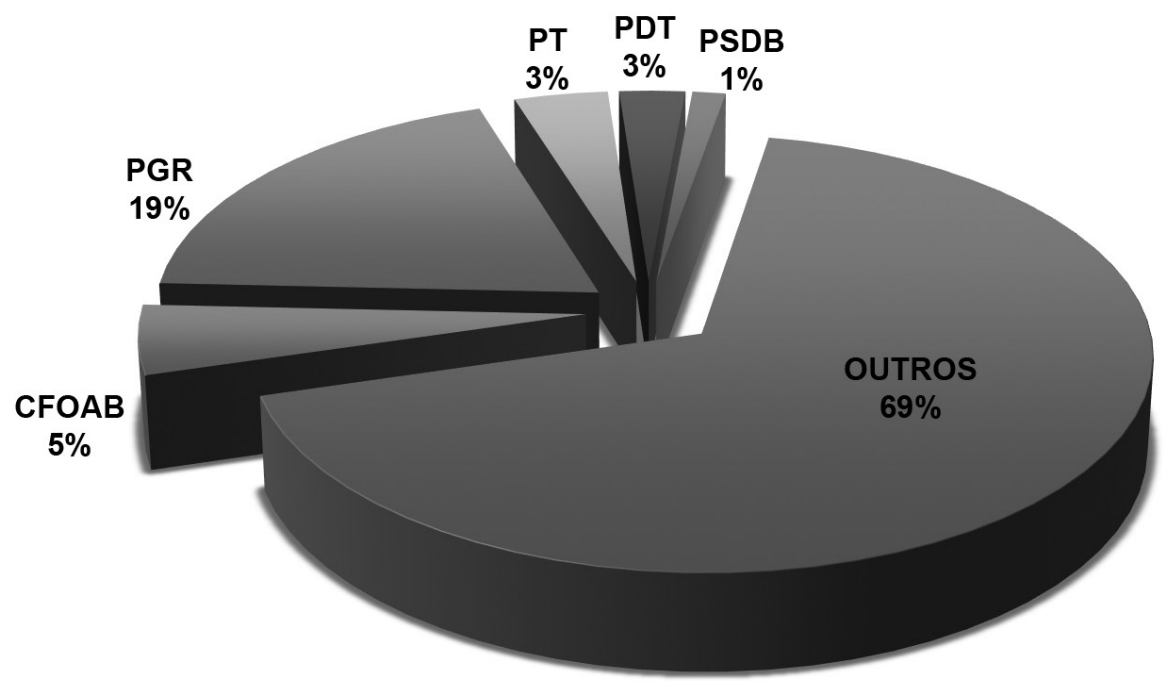

Gráfico 1 - Porcentagem de ADIs propostas pelo CFOAB e demais legitimados ativos entre 1988 e maio de 2013.

\footnotetext{
As tabelas e gráficos foram publicados em artigo EMERIQUE, L. B. e LARA, H. B. L. "Sociedade aberta dos intérpretes da Constituição e a participação do Conselho Federal da Ordem dos Advogados do Brasil no controle concentrado de constitucionalidade" In: Revista do Instituto de Hermenêutica Jurídica. Belo Horizonte: Fórum, ano 13, n. 18 , jul./dez. 2015 , p. $145-170$.
} 
Entre outubro de 1988 e maio de 2013 no exercício do controle concentrado de constitucionalidade foram propostas 4.764 ADIs no STF, conforme previsão do art. 103, CRFB/88, sendo:

- 19\% demandadas pela Procuradoria Geral da República;

- 5\% pelo Conselho Federal da OAB;

- 3\% pelo Partido dos Trabalhadores;

- 3\% pelo Partido Democrático Trabalhista;

- 1\% pelo Partido da Social-Democracia Brasileira.

No conjunto das ADIs propostas dentre os legitimados ativos universais, o gráfico revela que o maior demandante é o PGR, o que pode ser justificado, ao menos em parte, em razão do traço histórico do controle concentrado sempre ter conferido a este a legitimidade ativa para propositura de açôes desta natureza.

Todavia, há que se destacar a participação ativa e incisiva do CFOAB no controle de constitucionalidade, sendo este o segundo maior demandante no conjunto dos legitimados ativos universais, superior, inclusive, ao número de açóes propostas, em separado, por cada um dos partidos políticos com representação no Congresso Nacional, não obstante sejam canais representativos relevantes no processo democrático.

O gráfico confirma o papel propositivo do CFOAB num cenário de sociedade aberta dos interpretes da constituição que prima pela pluralidade e diálogo com a sociedade e indica que a abertura do rol dos legitimados ativos para propositura de ADIs trouxe um ganho efetivo na exploração de novas oportunidades de discussóes sobre a constitucionalidade das leis e atos normativos junto ao STF.

\section{Situação das ADIs}

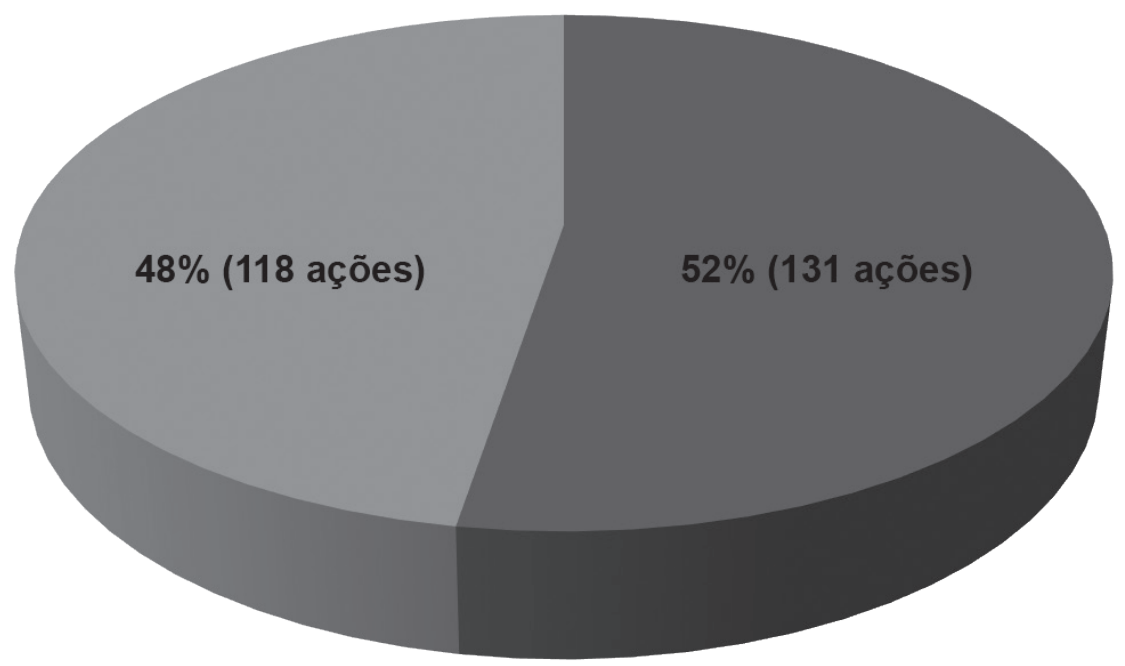

Julgada $\quad$ Aguardando Julgamento

Gráfico 2 - Apresenta a situação de julgamento pelo STF das ADIs propostas pelo CFOAB entre 1988 e 2013. 
(até maio):

O gráfico indica que dentre as 249 ADIs propostas pelo CFOAB entre 1988 e 2013

- mais da metade (52\% - 131 casos) já foram julgadas pelo STF

- enquanto que 48\%, ou seja, 118 demandas aguardam julgamento pelo STF.

Tendo em perspectiva que nos últimos anos ocorreu um crescimento progressivo das demandas acionadas pelo $\mathrm{CFOAB}$, houve um quantitativo razoável de julgamento pelo STF das açóes propostas, mas ainda existe um volume considerável de ações que esperam pelo seu julgamento pelo guardiáo da Constituição.

Ainda em consideraçáo as açóes julgadas, cumpre indicar os resultados obtidos.

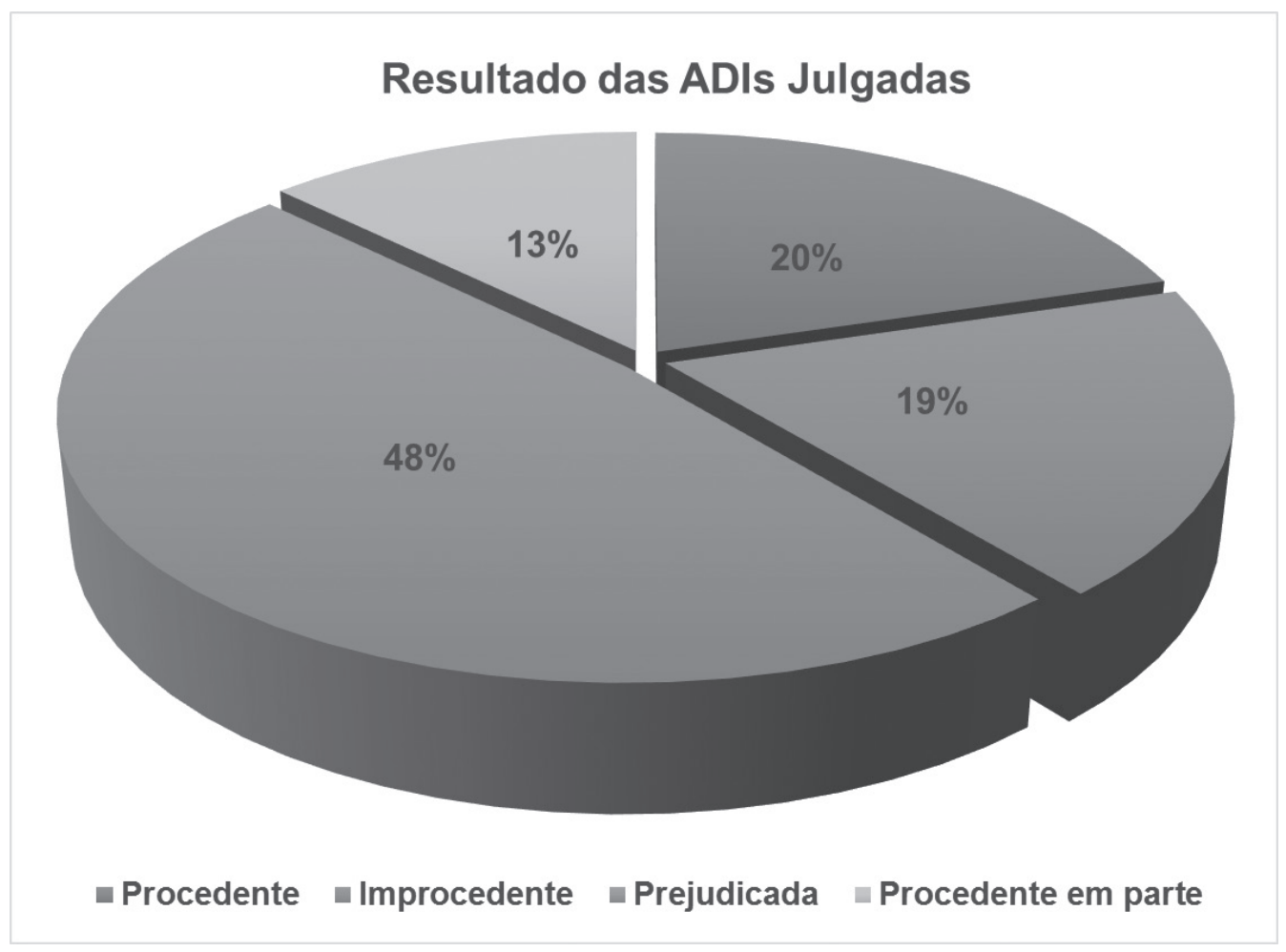

Gráfico 3 - Resultado das ADIs propostas pelo CFOAB entre 1988 e 2013 julgadas pelo STF.

O gráfico indica os seguintes resultados dos julgamentos pelo STF das ADIs propostas pelo CFOAB entre os anos de 1988 e 2013 (até maio):

- $20 \%$ foram julgadas procedentes;

- 19\% foram improcedentes;

- $13 \%$ foram procedentes em parte;

- $48 \%$ foram prejudicadas. 
O grande número de ações julgadas "Prejudicadas" (48\%) se refere àquelas cujo objetivo teria se extinguido em decorrência de mudança na própria legislação que revogou a lei questionada ou o julgamento pelo STF da mesma matéria alvejada em ação proposta por outro legitimado ativo.

Assim, os gráficos 2 e 3 demonstram que as $\mathrm{ADIs}$ propostas pelo CFOAB conseguem gerar resultados práticos positivos ao serem apreciadas pelo STF e muitas vezes julgadas totalmente procedentes $(20 \%)$ ou parcialmente procedentes (13\%), resultando em cerca de $1 / 3$ de procedência das demandas. $O$ que leva a supor que há um compromisso demandante sério, evitando propositura de ações despropositadas e/ou aventureiras, mas antes mostrando uma acuidade de qualificação técnica e o cuidado na escolha das matérias que figuram nas demandas levadas ao STF, que reconhece, em certa medida, a assertividade do questionamento suscitado pelo CFOAB.

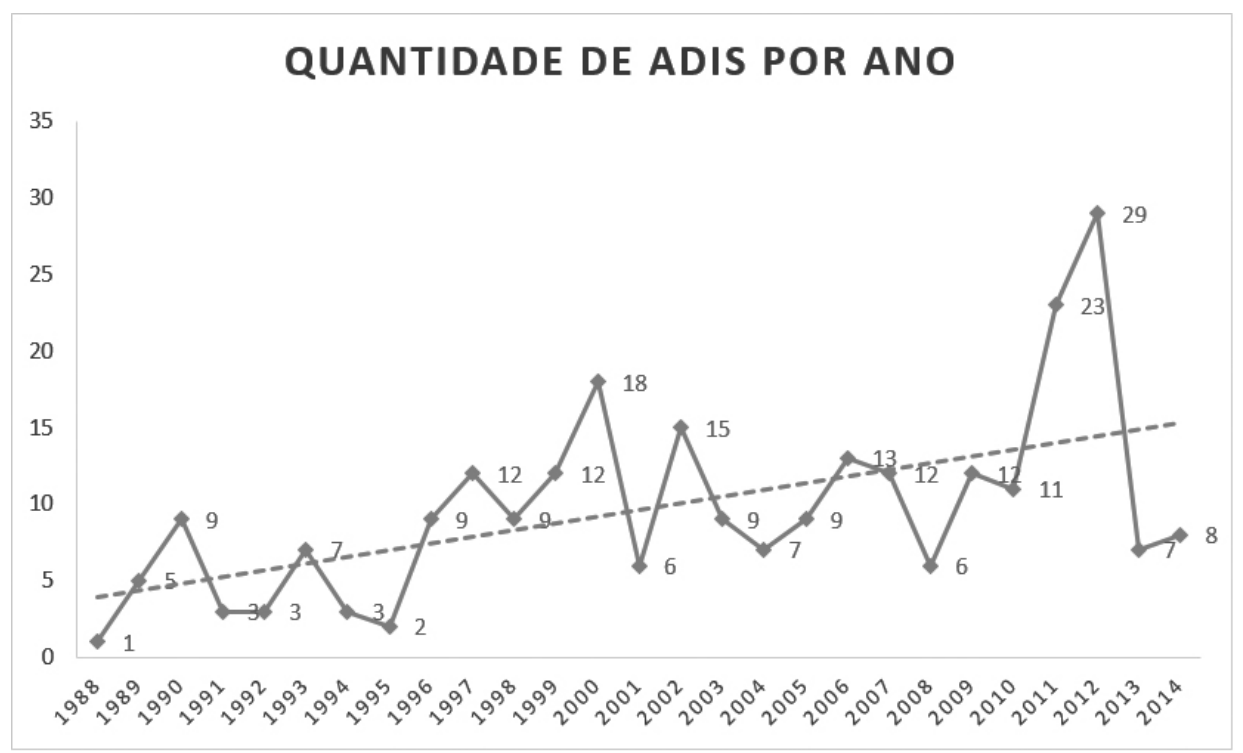

Gráfico 4 - Distribuição por ano das ADIs propostas junto ao STF pelo CFOAB entre outubro de 1988 até dezembro de 2014.

O gráfico revela a distribuição anual do quantitativo de ADIs propostas entre 1988 e 2014 pelo CFOAB, sendo:

\begin{tabular}{|c|c|}
\hline Ano de propositura da ADI & $\begin{array}{c}\text { Quantidade de ADI propostas } \\
\text { pelo CFOAB }\end{array}$ \\
\hline 1988 & 1 \\
\hline 1989 & 5 \\
\hline 1990 & 9 \\
\hline 1991 & 3 \\
\hline 1992 & 3 \\
\hline
\end{tabular}




\begin{tabular}{|c|c|}
\hline 1993 & 7 \\
\hline 1994 & 3 \\
\hline 1995 & 3 \\
\hline 1996 & 9 \\
\hline 1997 & 12 \\
\hline 1998 & 9 \\
\hline 1999 & 12 \\
\hline 2000 & 18 \\
\hline 2001 & 6 \\
\hline 2002 & 15 \\
\hline 2003 & 9 \\
\hline 2004 & 7 \\
\hline 2005 & 9 \\
\hline 2006 & 13 \\
\hline 2007 & 12 \\
\hline 2008 & 6 \\
\hline 2009 & 12 \\
\hline 2010 & 11 \\
\hline 2011 & 23 \\
\hline 2012 & 29 \\
\hline 2013 & 7 \\
\hline 2014 & 8 \\
\hline
\end{tabular}

Tabela 1- Quantitativo de ADIs propostas junto ao STF pelo CFOAB entre os anos de 1988 e 2014.

Há uma tendência confirmada no gráfico e na tabela que sugere que o papel do $\mathrm{CFOAB}$ no controle de constitucionalidade vem crescendo a cada ano em quase duas décadas e meia que goza de legitimidade universal para proposituras de ADIs junto ao STF, encontrando o seu ápice nos anos de 2011 (23 açôes) em 2012 (29 açóes).

Apesar desta presença mais significativa no volume de demandas propostas pelo $\mathrm{CFOAB}$, não há uma consequente confirmação de que a abertura da sociedade dos intérpretes da constituição nos moldes previstos por Häberle, conduza a um aumento insustentável da quantidade de açóes demandadas na Corte constitucional. O instrumento tem sido utilizado com certa parcimônia e sem promover a sua banalização.

Antes, pelo contrário, a presença qualificada do CFOAB enquanto legitimado ativo universal para demandar em matéria de controle concentrado de constitucionalidade, confirma a tese de Häberle. Pois há um ganho efetivo para a sociedade com a abertura do rol de intérpretes da constituição, visto que a interpretaçấo constitucional não fica circunscrita com exclusividade a uns poucos, porém se torna um empenho coletivo, republicano e democrático, agregando a sociedade no processo, de modo que esta assume a função de intérprete e destinatária da norma constitucional. 


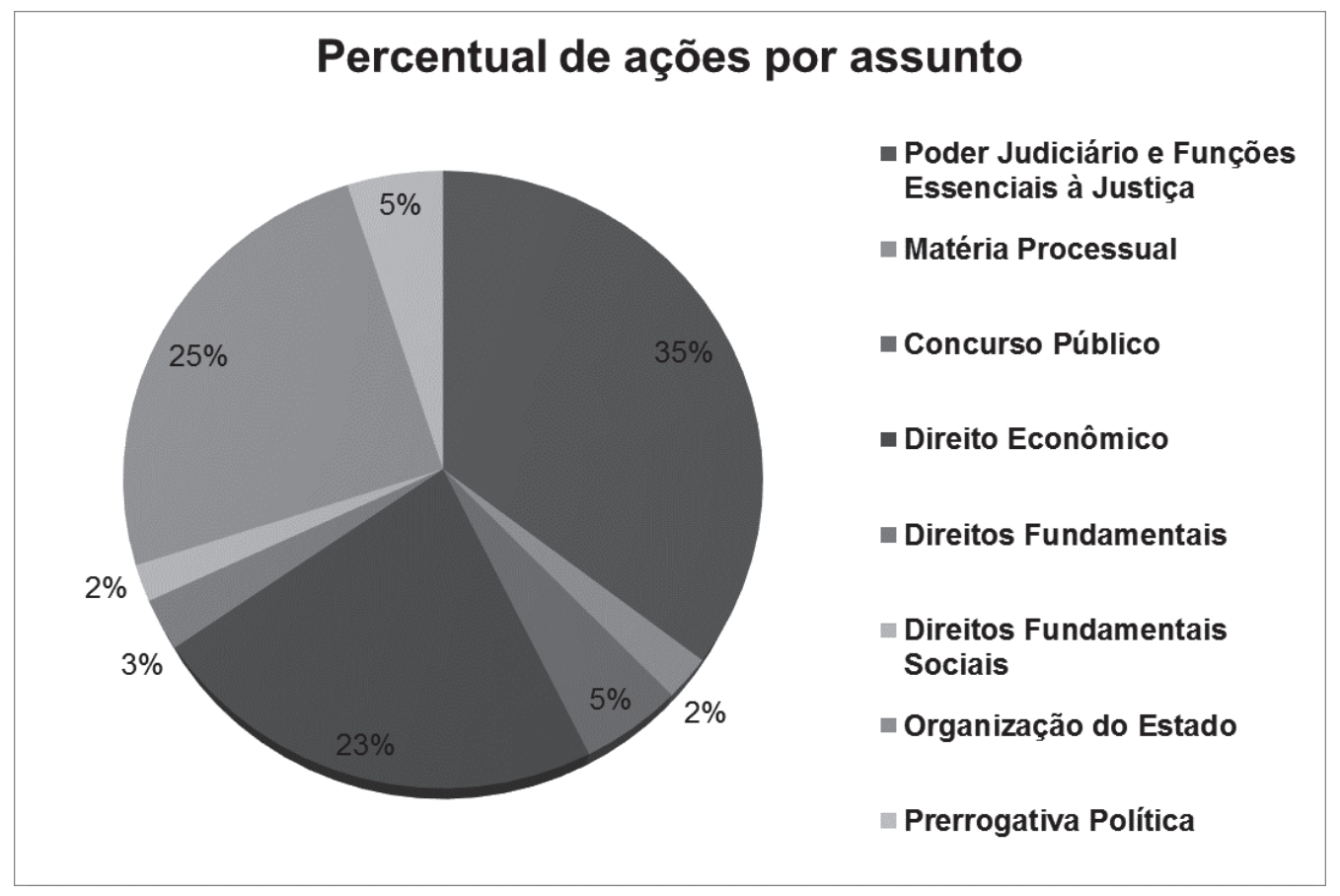

Gráfico 5 - Percentual de ADIs propostas pelo CFOAB por matérialassunto entre 1988 e 2014.

O Gráfico acima divide as 260 ADIs propostas pelo CFOAB entre outubro de 1988 e dezembro de 2014 em matérias/assuntos e demostra qual foi o percentual de cada assunto demandado pelo CFOAB que pode ser assim descrito:

- Poder Judiciário e Funções Essenciais à Justiça: 35\% (92 casos);

- Matéria Processual: 2\% (6 casos);

- Concurso Público: 5\% (13 casos);

- Direito Econômico: 23\% (59 casos);

- Direitos Fundamentais: 3\% (7 casos);

- Direitos Fundamentais Sociais: 2\% (5 casos);

- Organização do Estado: 25\% (65 casos);

- Prerrogativa Política: 5\% (13 casos).

Há uma diversidade de temas abarcados no controle concentrado realizado pelo Conselho Federal, com destaque para questóes relacionadas ao Poder Judiciário e funçóes essenciais à Justiça, o que se justifica pelo fato destes temas guardarem proximidade com o exercício das atividades profissionais de advocacia.

Dentre assuntos abordados podem ser mencionados problemas relativos à prestação jurisdicional e ao devido processo legal, bem como aspectos que questionam direitos fundamentais de natureza processual. Contudo, daí não se pode aferir que a legitimação ativa do CFOAB se reconduz a um papel corporativo desta categoria profissional, afastando-se de uma atuação que denote o perfil desejável numa sociedade aberta de intérpretes da consti- 
tuição. Aliás, caso este fosse o perfil majoritário da participação do $\mathrm{CFOAB}$, haveria indícios de um apelo meramente retórico e pouco prático da participação mais ampla da sociedade no processo de interpretação constitucional.

Todavia, o que se pode observar é que CFOAB demanda em temáticas de variadas naturezas, o que denota a importância que dá aos assuntos que extravasam o cotidiano meramente jurídico. Essa diversidade temática sugere que o CFOAB atua de forma diferenciada e cumpre o papel definido pela constituição de ser um agente amplo que proponha $\mathrm{ADIs}$ sobre todos os temas, não apenas àqueles pertinentes a sua categoria.

Essa assertiva não significa que a $\mathrm{OAB}$ não proponha $\mathrm{ADIs}$ em defesa dos advogados e sobre questóes diretamente ligadas ao meio jurídico, mas sim que além de cumprir esse papel, ela também aborda questôes ligadas aos direitos fundamentais (gerais e sociais), controle da corrupção, organizaçáo do Estado, tributação (inclusive e não apenas taxa judiciária), competências dos entes federativos etc.

Neste ponto, cumpre destacar o percentual em torno de 5\% de açôes envolvendo direitos fundamentais, agindo o CFOAB como verdadeiro canal de vocalizaçáo da sociedade civil na busca de meios jurídicos cabíveis para manutenção dos direitos e garantias expressos no texto constitucional, evitando o aviltamento dos seus comandos.

\section{CONSIDERAÇÕES FINAIS}

O estudo da jurisdição constitucional tradicionalmente tem sido desenvolvido com foco no método de seu exercício e no resultado proferido pelas Cortes Constitucionais. Contudo, torna-se necessário ampliar o debate para discutir o papel dos atores no processo de interpretação constitucional, uma vez que a sociedade também tem significativas contribuições para a construção da realidade constitucional, sendo impróprio observá-la tão somente como mera destinatária dos resultados dos processos.

A análise empírica efetuada em relação às $\mathrm{ADIs}$ demandadas pelo CFOAB entre os anos de 1988 e 2014 perante o STF, a partir do banco de dados construído na pesquisa e o tratamento dos dados levantados permitem-nos concluir que o papel desempenhado pelo Conselho Federal da Ordem dos Advogados do Brasil enquanto legitimado ativo para propositura de açóes direta de controle de constitucionalidade corrobora para a afirmação dos ideais de Häberle em torno da sociedade aberta dos intérpretes da constituição, visto que estas açóes constitucionais visam atender a coletividade e não exclusivamente, e nem mesmo preferencialmente, a proteção das prerrogativas de classe.

Assim, pode-se concluir que representa um resultado positivo no processo de democratização procedimental para a sociedade com a abertura do conjunto de intérpretes da constituição e, em particular, com a figuração do CFOAB como ator no processo de controle concentrado de constitucionalidade brasileiro, visto que a interpretaçáo constitucional não fica restringida unicamente a uns poucos, entretanto se configura como um compromisso coletivo, republicano e democrático, unindo a sociedade no processo, de maneira que esta avoca tanto a função de intérprete como de destinatária da norma constitucional.

Daí poder-se afirmar que a ampliação do rol dos legitimados ativos no processo de controle de constitucionalidade com a Constituição de 1988 trouxe um ganho efetivo para a manifestação do espírito democrático e republicano, da publicidade e do pluralismo, pelo menos no que toca a análise sobre a participaçáo do CFOAB no controle de constituciona- 
lidade brasileiro na condição de demandante e este ganho repercute no campo dos direitos fundamentais de forma direta.

\section{REFERÊNCIAS:}

BELLO FILHO, Ney de Barros. Sistema constitucional aberto. Belo Horizonte: Del Rey, 2003.

BULHÓES, M. G. P. Plano Nacional de Qualificação do Trabalhador no Rio Grande do Sul/Brasil: avanços e limites na participação de atores governamentais e não governamentais. In: MILANI, C; ARTURI, C. \& SOLINÍS, G. (Orgs.) Democracia e governança mundial; que regulaçóes para o século XXI? Porto Alegre: UFRGS, UNESCO, 2002.

CAPPELLETTI, Mauro. O controle judicial de constitucionalidade das leis no direito comparado. 2a ed. Reimpressão. Porto Alegre: Sergio Antonio Fabris, 1984.

DAGNINO, E. Sociedade civil e espaços públicos no Brasil. In: DAGNINO, E. (org.) Sociedade civil e espaços públicos no Brasil. São Paulo: Paz e Terra, 2002.

EMERIQUE, Lilian Balmant. Direito fundamental como oposição política. Curitiba: Juruá, 2006.

e LARA, Halison Bruno de Lima. "Sociedade aberta dos intérpretes da Constituição e a participação do Conselho Federal da Ordem dos Advogados do Brasil no controle concentrado de constitucionalidade". In: Revista do Instituto de Hermenêutica Jurídica, Belo Horizonte: Fórum. Ano 13. n. 18, jul./dez. 2015, p. 145-170.

GRINDLE, M. S. \& THOMAS, J. W. Public Choices and Policy Change: the political economy of reform in developing countries. London: The Jonhs Hopkins University Press, 1991.

HABËRLE, Peter. Hermenêutica constitucional, a sociedade aberta dos intérpretes da Constituição: contribuição para a interpretação pluralista e "procedimental" da Constituição. Porto Alegre: Sergio Antonio Fabris, 1997.

HESSE, Konrad. A força normativa da constituiçáo. Porto Alegre: Sergio Antonio Fabris, 1991.

LÓPEZ, Tomás Requena. Sobre la función, los medios y los límites de la interpretación de la Constitución. Granada, Colmares, 2001.

MENDES, Gilmar Ferreira. Jurisdição constitucional. São Paulo: Saraiva, 1996.

. Homenagem à doutrina de Peter Häberle e sua influência no Brasil. Disponível em: <http://www.stf.jus.br/repositorio/cms/portalStflnternacional/portalStfAgenda_pt_br/anexo/Homenagem_a_Peter_Haberle_Pronunciamento_3_1.pdf>. Acesso em: 18 abr. 2016.

O pensamento de Peter Häberle na jurisprudência do Supremo Tribunal Federal. Observatório da Jurisdição Constitucional. Brasília: IDP, Ano 2, 2008/2009. Disponível em: <http://www.portaldeperiodicos.idp.edu.br/index.php/observatorio/article/viewFile/205/173>. Acesso em 18 abr. 2016.

MIDGLEY, J. Community Participation, Social Development and state. London: Methuen, 1986. 
PALU, Oswaldo Luiz. Controle de constitucionalidade. 2a ed. São Paulo: Revista dos Tribunais, 2001.

RAICHELES, R. Esfera pública e Conselhos de Assistência Social: caminhos da construção democrática. São Paulo: Cortez, 2000.

RIBEIRO, Renato Janine. A república. São Paulo: Publifolha, 2001.

RODRÍGUEZ-ARANA, Jaime. El ciudadano y el poder público: el princípioy el derecho al buen Gobierno y a le buena Administración. Madrid: Reus, 2012.

SANTOS JR, O. A. Democracia e governo local: dilemas da reforma municipal no Brasil. Rio de Janeiro: Revan, FASE, 2001.

SASTRE, Marta Gutiérrez. La participación em los servicios públicos de bienestar: um análisis del poder de los usuários em el ámbito de la salud, la educación e los servicios sociales. Madrid: Consejo Económico y Social, 2005.

SOUZA CRUZ, Álvaro Ricardo. Jurisdiçáo constitucional democrática. Belo Horizonte: Del Rey, 2004.

SOUZA NETO, Cláudio Pereira. Jurisdição constitucional, democracia e racionalidade prática. Rio de Janeiro: Renovar, 2002.

TATAGIBA, L. Os conselhos gestores e a democratização das políticas públicas no Brasil. In: DAGNINO, E. (org.) Sociedade civil e espaços públicos no Brasil. São Paulo: Paz e Terra, 2002.

UGALDE, A. Ideological dimensions of community participation in Latin America health programs. Social Science and Medicine, v. 1, p. 41-53, 1985.

VERDÚ, Pablo Lucas. O sentimento constitucional: a aproximação ao estudo do sentir constitucional como modo de integração política. Rio de Janeiro: Forense, 2004.

\section{Lilian Marcia Balmant Emerique}

lilamarcia@gmail.com

Pós-doutorado em Ciências Jurídico-políticas pela Universidade de Lisboa (Portugal 2007), Doutorado em Direito pela Pontifícia Universidade Católica de São Paulo (2004), Mestrado em Direito pela Pontifícia Universidade Católica do Rio de Janeiro (1996) e Mestrado em Ciência Política e Relaçóes Internacionais pela Universidade Nova de Lisboa - especialização em Globalização e ambiente (2010). Equivalência (revalidação do diploma) do Doutorado em Direito pela Universidade de Lisboa (Portugal - 2008). Professora e pesquisadora na área de Direito, Ciência Política e Relaçóes Internacionais. Professora adjunta da Faculdade Nacional de Direito e Coordenadora-Adjunta do Programa de Pósgraduação em Direito da Universidade Federal do Rio de Janeiro.

\section{Verônica Ferreira Noronha de Barros}

Graduação em andamento em Direito. Universidade Federal do Rio de Janeiro.

\section{Mariana Moretti Ribeiro}

Graduanda em Direito na Faculdade Nacional de Direito na Universidade Federal do Rio de Janeiro; estagiária na Defensoria Pública Geral do Estado do Rio de Janeiro 